\title{
Refractory Endometrial Carcinoma
}

National Cancer Institute

\section{Source}

National Cancer Institute. Refractory Endometrial Carcinoma. NCI Thesaurus. Code C150093.

Endometrial carcinoma that is resistant to treatment 